ANL-7039

Argonne גational Laboratom

EVALUATION OF A

THERMIONIC ENERGY CONVERTER

USING FILM-BOILING LIQUID METAL

A. J. Ulrich

$$
\text { by }
$$




\section{DISCLAIMER}

This report was prepared as an account of work sponsored by an agency of the United States Government. Neither the United States Government nor any agency Thereof, nor any of their employees, makes any warranty, express or implied, or assumes any legal liability or responsibility for the accuracy, completeness, or usefulness of any information, apparatus, product, or process disclosed, or represents that its use would not infringe privately owned rights. Reference herein to any specific commercial product, process, or service by trade name, trademark, manufacturer, or otherwise does not necessarily constitute or imply its endorsement, recommendation, or favoring by the United States Government or any agency thereof. The views and opinions of authors expressed herein do not necessarily state or reflect those of the United States Government or any agency thereof. 


\section{DISCLAIMER}

Portions of this document may be illegible in electronic image products. Images are produced from the best available original document. 


\section{LEGAL NOTICE}

This report was prepared as an account of Government sponsored work. Neither the United States, nor the Commission, nor any person acting on behalf of the Commission:

A. Makes any warranty or representation, expressed or implied, with respect to the accuracy, completeness, or usefulness of the information contained in this report, or that the use of any information, apparatus, method, or process disclosed in this report may not infringe privately owned rights; or

B. Assumes any liabilities with respect to the use of, or for damages resulting from the use of any information, apparatus, method, or process disclosed in this report.

As used in the above, "person acting on behalf of the Commission" includes any employee or contractor of the Commission, or employee of such contractor, to the extent that such employee or contractor of the Commission, or employee of such contractor prepares, disseminates, or provides access to, any information pursuant to his employment or contract with the Commission, or his employment with such contractor.

Printed in USA. Price $\$ 1.00$. Available from the Clearinghouse for Federal Scientific and Technical Information, National Bureau of Standards, U. S. Department of Commerce, Springfield, Virginia 
AN.L-7.039

Propulsion Systems and Energy Conversion (TID-4500, 44th Ed.)

AEC Research and

Development Report

ARGONNE NATIONAL LABORATORY

9700 South Cass Avenue

Argonne, Illinois 60440

$\checkmark$

EVALUATION OF A

THERMIONIC ENERGY CONVERTER USING FILM-BOILING LIQUID METAL

by

A. J. Ulrich

Reactor Physics Division

May. 1965

Operated by The University of Chicago under

Contract W-31-109-eng-38

with the

U. S. Atomic Energy Commission 
TABLE OF CONTENTS

$\underline{\text { Page }}$

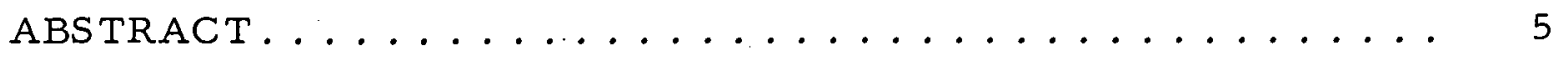

I. INTRODUCTION..................... 5

II. PROOF-OF-PRINCIPLE EXPERIMENT; SHORT - TERM

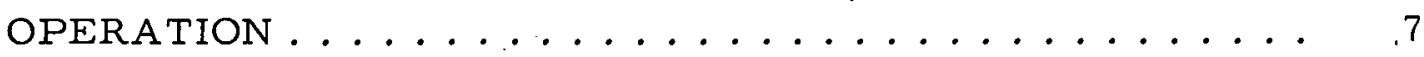

III. POSSIBLE EXPERIMENTAL DIODE GEOMETRIES . . . . . 7

IV. DIODE FOR CONTINUOUS OPERATION. . . . . . . . . 8

V. EXPERIMENTAL STUDY OF FILM-BOILING STABILITY . ... 12

VI. EXPERIMENTAL COMPONENT DEVELOPMENT . . . . . 15

VII. DESIGN LIMITATIONS IMPOSED BY EXPERIMENTAL

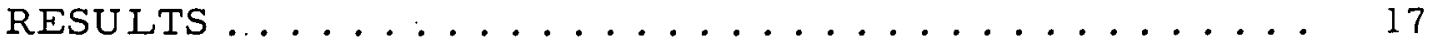

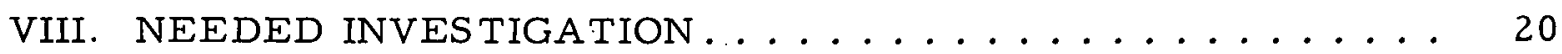

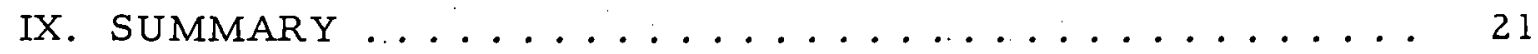

APPENDIX: LIQUID-LEVEL MEASUREMENT . . . . . . . . 22

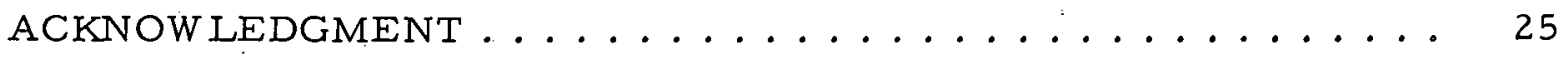

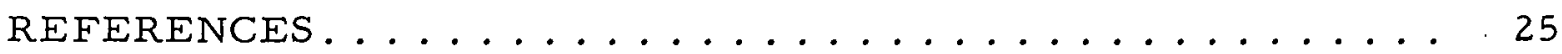


LIST OF FIGURES

No.

Title

Page

1. Two Possible Liquid-Metal Diode Geometries in the Normal

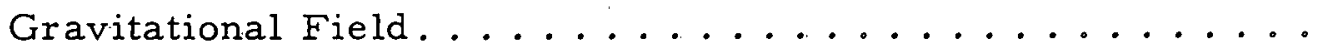

2. Diode with Liquid-Metal Electron Collector ..........

3. Reconstruction of Shape of Pool Depression from Elevation

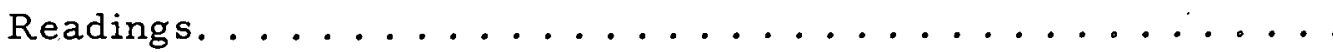

4. Calibration of Collector Thermocouple by Boiling-point Determinations with Potassium..............

5. Calibration of Collector Thermocouple by Boiling-point

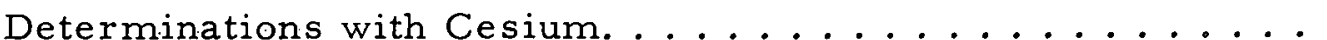

6. Cesium-diode Current-voltage Curve for Tantalum Emitter Temperature $2000^{\circ} \mathrm{K}$, Collector Temperature $550^{\circ} \mathrm{K}$, Saturation Temperature $635^{\circ} \mathrm{K}$, and Cesium Pressure 7.74 Torr . . .

7. Effect of Emitter, Collector, and Pool Saturation Temperatures on Maximum Submersion of Emitter in Potassium Pool, with Emitter Temperature at $2025^{\circ} \mathrm{K} \ldots \ldots \ldots$

8. Effect of Emitter, Collector, and Pool Saturation Temperatures on Maximum Submersion of Emitter in Potassium Pool, with Emitter Temperature at $2240^{\circ} \mathrm{K} \ldots \ldots \ldots \ldots$

9. Effect of Emitter, Collector, and Pool Saturation Temperatures on Maximum Submersion of Emitter in Potassium Pool, with Emitter Temperature at $2440^{\circ} \mathrm{K} \ldots \ldots \ldots$

10. Effect of Emitter, Collector, and Saturation Temperatures on Maximum Submersion of Emitter in Cesium Pool, with Emitter Temperature at $1810^{\circ} \mathrm{K} \ldots \ldots \ldots \ldots$

11. Effect of Emitter, Collector, and Saturation Temperatures on Maximum Submersion of Emitter in Cesium Pool, with Emitter Temperature at $2010^{\circ} \mathrm{K} \ldots \ldots \ldots \ldots$

12. Effect of Emitter, Collector, and Saturation Temperatures on Maximum Submersion of Emitter in Cesium Pool, with Emitter Temperature at $2230^{\circ} \mathrm{K} \ldots \ldots \ldots \ldots$ 


\section{LIST OF FIGURES}

No.

Title

Page

13. Thermal-divider Model Using Water as the Liquid........ 16

14. Cross Section of Typical In-core Thermionic Fuel Element...

15. Cesium Pool Reflections Based on Object Elevation Differences of $0.1 \mathrm{~cm} \ldots \ldots \ldots \ldots \ldots \ldots$

16. Extrapolated Submersion versus Apparent Submersion in

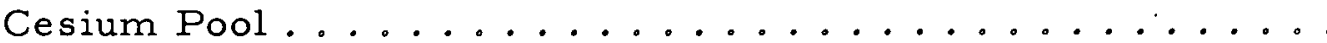




\title{
EVALUATION OF A \\ THERMIONIC ENERGY CONVERTER \\ USING FILM-BOILING LIQUID METAL
}

by

A. J. Ulrich

\begin{abstract}
The conventional plasma thermocouple or thermionic energy-conversion diode has a solid-metal electron collector. In this report, a thermionic energy-conversion diode is evaluated which uses a liquid metal as the electron collector. Liquids such as cesium, rubidium, or potassium and their alloys, are separated from the hot emitter by the vapor film produced in film boiling. Such a vapor film would maintain electrical separation if the emitter became warped due to radiation damage, thus greatly improving the reliability of the in-core thermionic diode.

In an experiment, it is found that stable film boiling occurs for ranges of emitter temperatures and of cesium and potassium vapor pressures which are appropriate for thermionic diodes. The typical thermionic, seriesconnected, fuel-element geometry can be used in a filmboiling liquid-metal design to produce power in the zero-g field of space. If this is done, the price that must be paid for the improved tolerance to radiation damage and emitter evaporation in this type of space application is primarily more precise control of collector temperatures, a modified startup and shutdown schedule to avoid nucleate boiling, and further development of a new thermal divider to exclude nucleate boiling at the edges of the collector surfaces.
\end{abstract}

\section{INTRODUCTION}

Heat can be converted to electrical energy by using thermionically emitted electrons as a working fluid, thus avoiding turbines and generators. In its simplest form, high-temperature heat is supplied to a hot emitter. Electrons are boiled from the emitter surface and flow through a neutral plasma composed of electrons and ions to a relatively cold electron collector from which low-temperature waste heat is then removed. The neutral 
plasma eliminates space charge, which would otherwise greatly diminish the current of electrons from the emitter to the collector. Thermal energy in the emitter is converted to potential energy during emission as the electrons are raised from the Fermi level over the high work-function barrier at the surface of the emitter. A fraction of this potential energy goes back into thermal energy when the electrons enter the surface of the cold collector with its low work function and fall to the Fermi level of the collector. The rest of the potential energy is available to do useful work as the electrons flow back from collector to emitter through an external load.

The conventional plasma thermocouple or thermionic energyconversion diode has a solid-metal electron collector. Cesium vapor at a pressure of a few Torr or less is widely used to provide ions for electron space-charge neutralization. Under usual conditions, a layer of cesium coats the collector, so that electrically the collector appears to be cesium. This suggests the use of a diode with a liquid-metal collector material such as cesium, rubidium, or potassium and their alloys, separated from the hot emitter by the vapor film produced in film boiling. $(1-4)$ In such a diode, the metal vapor pressure can be brought in the range of a few Torr or less by, for example, controlling the pressure of an inert gas blanket which covers the film-boiling liquid. The boiling point is then fixed. If conditions in the vapor film are appropriate for existence of a plasma, a thermionic energyconversion plasma diode results.

Dimensional changes in the emitter produced by thermal effects or radiation damage may cause a short circuit in a conventional thermionic diode because of close spacing between the emitter and the collector. However, in this film-boiling diode, the vapor film would maintain electrical separation even if the emitter were to become warped. Thus the reliability of a thermionic power reactor using this type of diode would be greatly increased.

One source of heat loss... in the thermionic energy-conversion diode is thermal radiation from the emitter to the collector. Refractory metals used as emitter material can be polished sufficiently so that even with a tarnished collector the radiation loss. is not prohibitive. However, some emitter materials, such as uranium carbide and zirconium carbide, are good thermal radiators. Then, with a collector blackened by evaporated material, the radiation loss causes a noticeable reduction in efficiency. Use of a liquid-metal electron collector, with emitters that are good thermal radiators, reduces radiant-energy loss because of the high reflectivity of all the appropriate liquid metals. This reduction will remain in effect over the entire life of the converter, provided the evaporated material is wetted by the liquid metal. This reduction can also be viewed as some degree of relaxation of the low vapor-pressure limitation on cathode materials. This relaxation is applicable only to emitter materials that are good thermal radiators. 


\section{PROOF-OF-PRINCIPLE EXPERIMENT; SHORT-TERM OPERATION}

To obtain preliminary information on the feasibility of the filmboiling concept, a proof-of-principle experiment was performed.(2)

Drops of liquid metal were guided down a copper wire in an argon atmosphere into a tantalum cup heated from below by electron bombardment. The temperature of the cup was in the film-boiling range, causing a film of vapor to exist between the liquid and the heated tantalum. The copper wire remained in contact with the drop, acting as an electroncollector lead wire for the diode whose electron emitter was the tantalum cup.

The diode operated satisfactorily for the order of minutes as an energy converter with sodium-potassium alloy. In addition, the heattransfer rate across the film-boiling gap could be estimated by using the rate of evaporation of the drop and correcting for losses such as heat conducted along the copper-lead wire. The value of heat-transfer rate obtained was $11 \mathrm{~W} / \mathrm{cm}^{2}$, or about one-sixth of the black-body radiation for the temperatures involved, which is not prohibitive. (2)

\section{POSSIBLE EXPERIMENTAL DIODE GEOMETRIES}

To determine more precisely. the conditions under which the filmboiling process could be used in this application, further experiments with, continuous operation were necessary.

In this type of vapor diode, the electron emitter is first heated to a temperature that will produce film boiling. This temperature is also about that required to cause emission of sufficient thermionic electrons for the energy-conversion process. The liquid metal, which acts as an electron collector, is then brought close to the hot emitter, so that they are separated only by the sheath of vapor produced in film boiling, as is shown in Figure 1. Here two possible diode geometries appear, which could be used in the normal gravitational field. Film-boiling behavior was first studied qualitatively by means of models of both geometries using water, with parts made from glass, ceramic, and metal. Heat was applied to the simulated emitters by means of a flame.

In the top diagram of Figure 1, the emitter is introduced through the minuscus, and vapor generated under the emitter leaks out to the sace above the pool. In the lower diagram, the emitter enters the bottom of the pool through an insulating.seal, and the vapor does not leak from the sheath to the space above the pool except in the form of bubbles. In both diodes, to make the separation between the electrodes thin enough for use in energy conversion, the liquid metal must be subcooled, which means that the liquid metal 
is below its boiling point at the pressure inside the diode. This not only makes the sheath thin in both diodes but also completely suppresses the formation of bubbles in the lower diode. Because of the difference in vapor flow for these two geometries, the factors affecting the required vaporgeneration rate and the stability of the film-boiling sheath in the two cases are somewhat different.

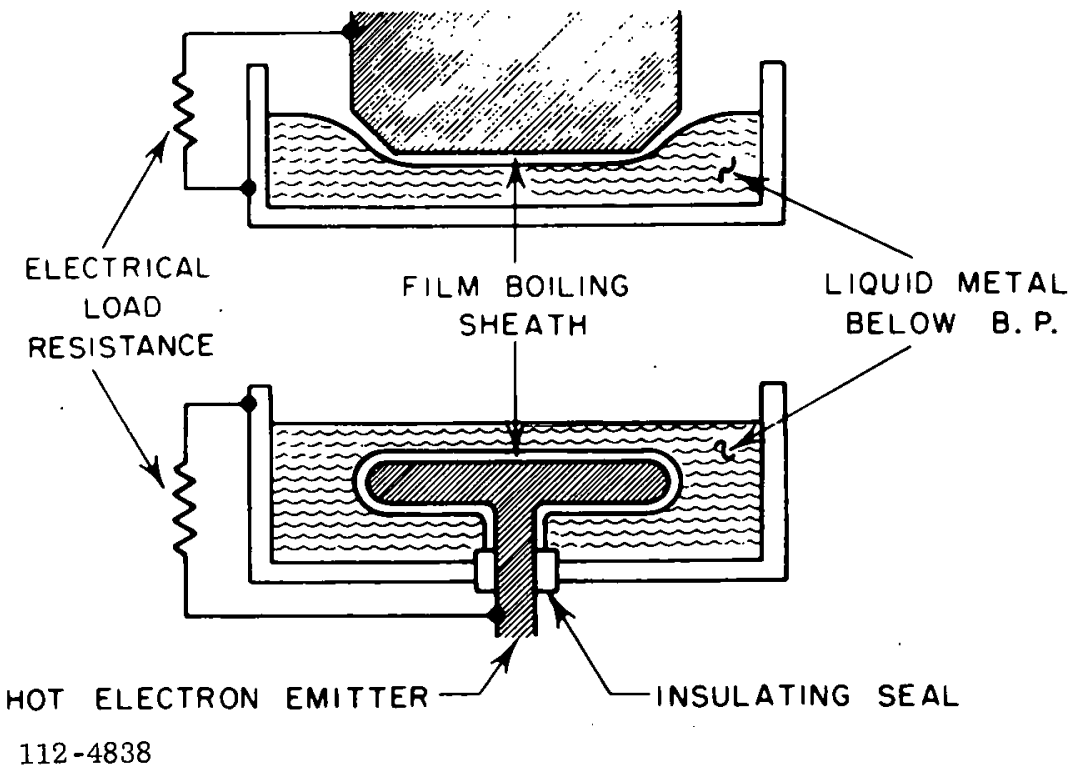

Fig. 1. Two Possible Liquid-Metal Diode Geometries in the Normal Gravitational Field

\section{DIODE FOR CONTINUOUS OPERATION}

To avoid the immediate development of the insulating seal needed in the lower geometry of Figure l, the next experiments investigated the conditions necessary for the maintenance of a stable sheath using the upper geometry. The development of the insulating seal was pursued in separate experiments described in Section VI on Experimental Component Development.

A cross-sectional drawing of the experimental diode is presented in Figure 2. The diode is heated by an electron gun, which occupies the center section. The filament and focusing cone are just above a tantalum cylinder, which acts as an electron emitter. The cylinder is chamfered at $45^{\circ}$ and has a polished bottom (1.13-cm diameter). The electron-gun assembly is isolated by an enclosure made of tantalum and stainless steel. The liquidmetal electron collector is contained in the conical copper cup immediately below the tantalum emitter. The silicone oil cooling jacket is below the copper cup, and the line through which liquid metal is admitted extends to the left. Metal vapor evolved from the liquid rises through the annular space 
outside the electron-gun assembly and condenses on copper fins attached to the outside wall. The top of the chamber that contains the liquid metal and the top of the emitter assembly are cooled by water coils. The emitter assembly is electrically insulated from the chamber by a thin Teflon gasket between the flanges that carry the rubber O-ring seal. Both the gun and the liquid-metal chamber are continuously pumped by a liquid-nitrogen cold trap and a mechanical forepump. The liquid-metal chamber can be isolated and filled with a low-pressure, argon gas blanket. The gas enters through an opening not shown, just above the condenser fins.

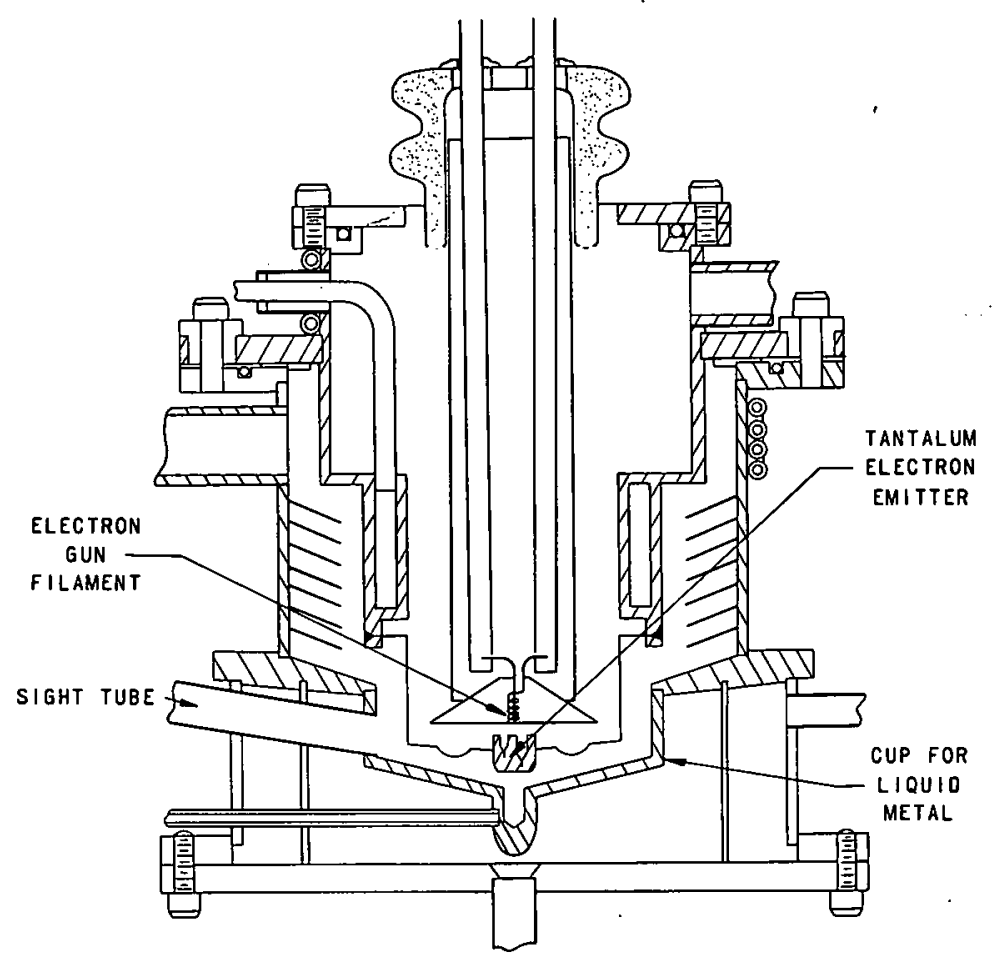

Fig. 2

Diode with Liquid-Metal Electron Collector

$112-1501$

The emitter temperature is determined from pyrometer readings taken through the gun assembly looking at black-body holes on the top side of the tantalum emitter. The temperature is corrected for window absorption and emitter temperature gradient. The estimated accuracy is $\pm 5^{\circ} \mathrm{K}$.

The level of the liquid-metal pool is determined by looking at its highly reflective surface through the sight tube with a telescope mounted on a cathetometer. Elevation measurements are made for a series of points on the emitter and for the same series of points on the image of the emitter reflected from the pool. Comparing these elevations enables the level of the flat portion of the pool to be determined within an estimated $\pm 10 \%$. Figure 3 shows diagrammatically how the shape of the depression in the pool caused by the film boiling on the emitter can be partially reconstructed from these readings and the laws of optics. Level measurements are discussed further in the Appendix. 


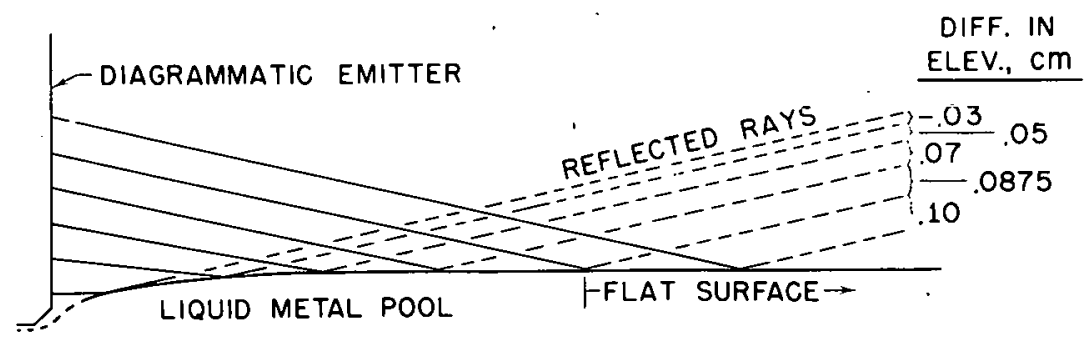

$112-4837$

Fig. 3. Reconstruction of Shape of Pool Depression from Elevation Readings

The boiling point or saturation temperature for the liquid was fixed by the argon pressure above the pool and was measured by a Dubrovin gauge.

The temperature of the copper cup that holds the liquid metal was determined by an attached thermocouple. (This is called the collector temperature.) The uncertainty in this temperature measurement is estimated to be $\pm 5^{\circ} \mathrm{K}$. Figure 4 shows the calibration of this thermocouple by

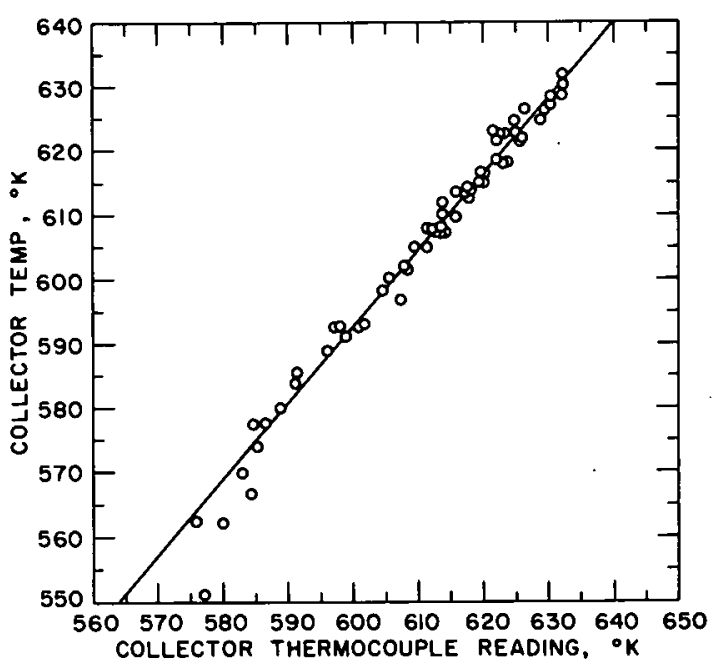

$112-4862$

Fig. 4. Calibration of Collector Thermocouple by Boilingpoint Determinations with Potassium means of boiling-point determinations and based on the published vapor pressure of potassium. (5) The thermocouple was also calibrated against the boiling point of cesium by means of the published relationship between the vapor pressure and the liquid temperature. (5) The cesium and potassium calibration curves are shown in Figure 5. The disagreement in calibrations, when translated into vapor pressure differences, averages to about $20 \%$. This is the uncertainty given by Honig for the vaporpressure data. (5)

It was demonstrated that stable film boiling, continuous for at least tens of hours, occurred for ranges of emitter temperatures and cesium and potassium vapor pressures that are useful for thermionic diodes. Current-voltage output characteristic curves using potassium for the electron collector have been reported. (4) These curves show qualitative agreement with similar curves for diodes with solid electrodes. A typical current-voltage characteristic for the film-boiling cesium diode appears in Figure 6 . The observed current is of the same order as the electron emission current from the same emitter material (tantalum) in cesium vapor at the same temperature and pressure. (6) Thus, the initial assumption that liquid and solid electron collectors would appear the same electrically is confirmed. 


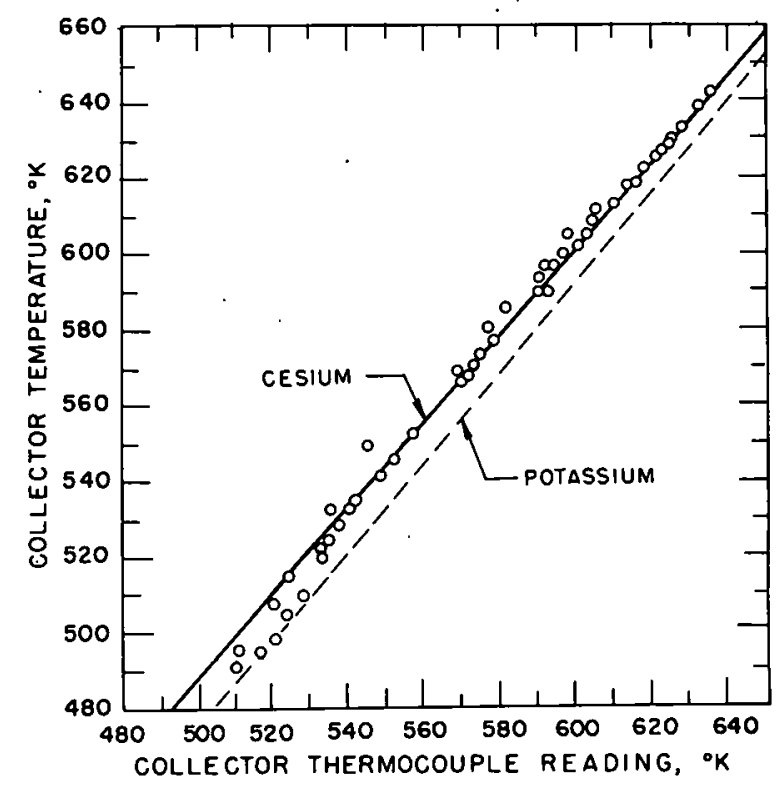

$112-4860$

Fig. 5. Calibration of Collector Thermocouple by Boiling-point Determinations with Cesium. (Calibration with Potassium Shown as Dashed Line.)

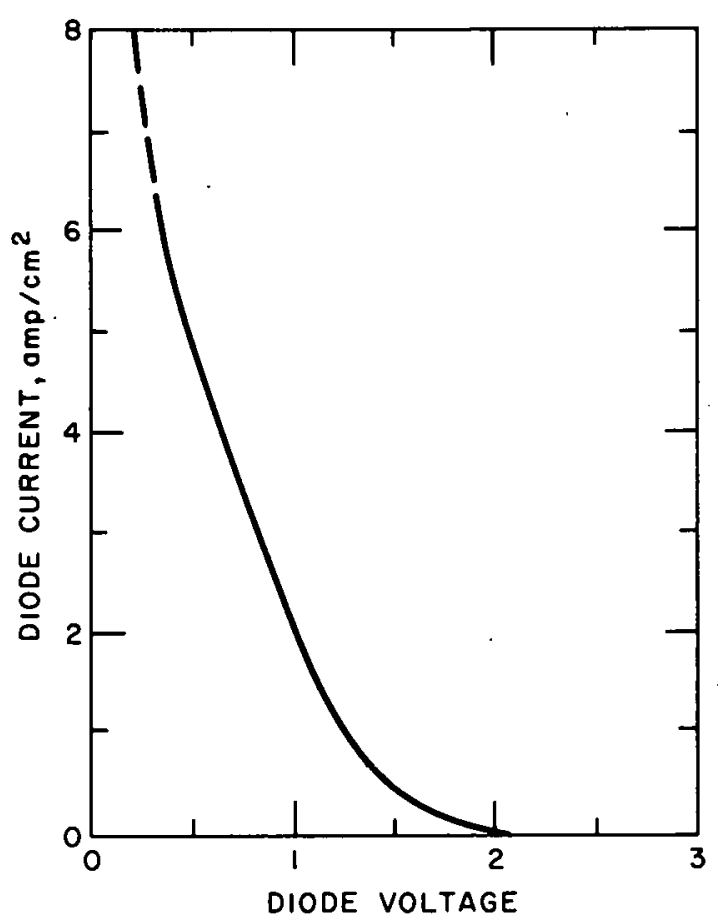

$112-4861$

Fig. 6. Cesium-diode Current-voltage Curve for Tantalum Emitter Temperature $2000^{\circ} \mathrm{K}$, Collector Temperature $550^{\circ} \mathrm{K}$, Saturation Temperature $635^{\circ} \mathrm{K}$, and Cesium Pressure 7.74 Torr

The spacing between the emitter and the liquid metal decreased as subcooling increased. It was estimated to be about $0.1 \mathrm{~mm}$ when the submersion was small, but the relationship between spacing and subcooling was not determined in these experiments.

The transient behavior on shutdown of electron-bombardment heat to the emitter did not immediately lead to the violent nucleate boiling that was anticipated. Figures 7 through 12 (in the next section) show that the film-boiling behavior in this region of operation is not strongly dependent on emitter temperature. The transition-boiling region between the filmboiling and nucleate-boiling regions is also broad. For a step-function shutdown, the time lag before violent nucleate boiling occurred might be of the order of $20 \mathrm{sec}$ for a fission-heated diode.

The above estimate is based on the following considerations: The temperature of the emitter was observed to drop from 2000 to $1600^{\circ} \mathrm{K}$ in approximately $5 \mathrm{sec}$ when electron-bombardment heating power was abruptly shut off. This is the time for the temperature to drop from a nominal operating temperature to the approximate temperature at which the transition between film boiling and nucleate boiling is first observed. A fissionheated emitter would have different heat-loss rates and heat-storage 
capacity, which would result in a cooling time about three times as long for a typical fission-heated design. In addition, the time for the temperature to drop through the transitional region to the nucleate boiling region might be about $5 \mathrm{sec}$. This brings the total estimated time from power shutoff until violent nucleate boiling to the order of $20 \mathrm{sec}$.

\section{EXPERIMENTAL STUDY OF FILM-BOILING STABILITY}

To determine feasibility, the bounds on the region of stable film boiling for representative liquid metals must be investigated. The apparatus shown in Figure 2 was used to obtain feasibility information for potassium and cesium.

Figure 7 gives some results for potassium with the emitter temperature $\mathrm{T}_{\mathrm{E}}$ at $2025^{\circ} \mathrm{K}$. The locations of the data points show the values of

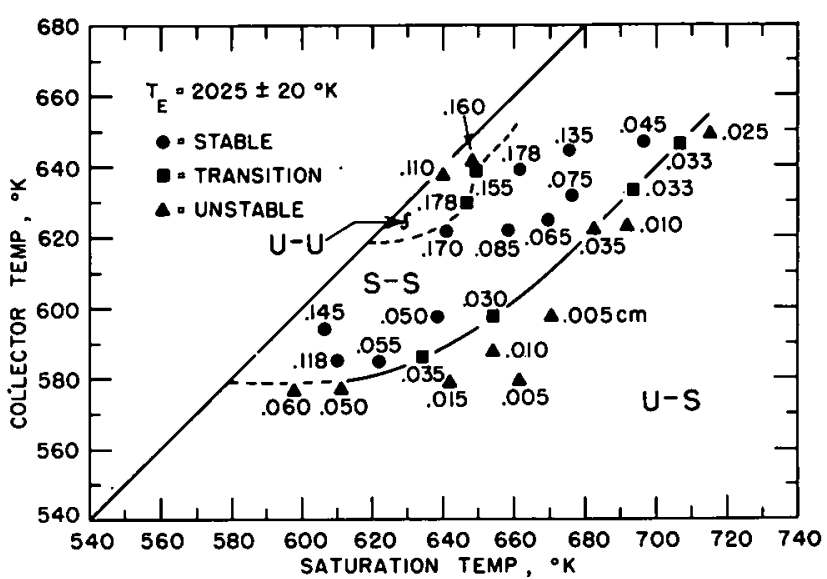

$112-4854$

Fig. 7. Effect of Emitter, Collector, and Pool Saturation Temperatures on Maximum Submersion of Emitter in Potassium Pool, with Emitter Temperature at $2025^{\circ} \mathrm{K}$. (Numbers given are in $\mathrm{cm}$.) saturation temperature and collector temperature that were chosen. Beside each data point appears the maximum submersion (in centimeters) that can be tolerated before the film-boiling mechanism becomes unsatisfactory. On the diagonal line, the collector temperature equals the saturation temperature. The data points would have fallen very near this line if a saturated liquid had been required for film boiling to exist. Therefore the deviation of the data points from the line is a measure of the subcooling of the liquid that can be tolerated and still have satisfactory film-boiling conditions. When the collector

temperature is below the boiling point, the vapor that is generated is rapidly condensed again and the film-boiling sheath is very thin; therefore the maximum submersion that can be tolerated is very small. Close to the saturation line, however, much greater submersions can be achieved.

When the maximum submersion is exceeded, three different types of limit are observed. In the lower right region,* U-S, unstable surface waves (i.e., of growing amplitude) are generated in association with intermittent shorting of the diode. In the central region,* S-S, stable (i.e., not growing) surface waves are generated in association with intermittent shorting of the diode. In the region nearest saturation,* $\mathrm{U}-\mathrm{U}$, unstable

* The regions in Figures 7-12 are designated U-S, S-S, and U-U to represent unstable upon shorting, stable upon shorting, and unstable even when unshorted, respectively. 
surface waves are generated which are large enough to modulate the electrical output characteristic, but do not short the diode. With still deeper submersion, shorting occurs, however. Data points on the boundary between two regions are indicated by squares. Places where the boundary is not welldefined by the data are indicated by a dashed line. The highest temperature for the potassium pool in this apparatus is established by the excessively high decomposition rate of the silicone oil coolant at temperatures above $650^{\circ} \mathrm{K}$.

Figure 8 gives emersion data for an emitter temperature of $2240^{\circ} \mathrm{K}$. Here the region of stable operation is larger, and maximum submersion is increased. Figure 9 shows submersion data for an emitter temperature of $2440^{\circ} \mathrm{K}$. Both the region of stable operation and the maximum submersion are further increased.

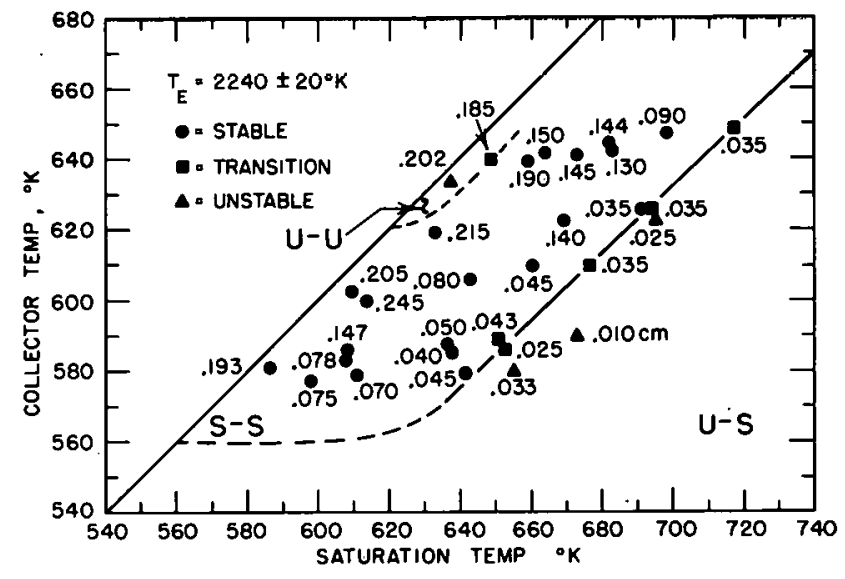

Fig. 8

Effect of Emitter, Collector, and Pool Saturation Temperatures on Maximum Submersion of Emitter in Potassium Pool, with Emitter Temperature at $2240^{\circ} \mathrm{K}$. (Numbers given are in $\mathrm{cm}$.)

$112-4856$

Fig. 9

Effect of Emitter, Collector, and Pool Saturation Temperatures on Maximum Submersion of Emitter in Potassium Pool, with Emitter Temperature at $2440^{\circ} \mathrm{K}$. (Numbers given are in $\mathrm{cm}$.)

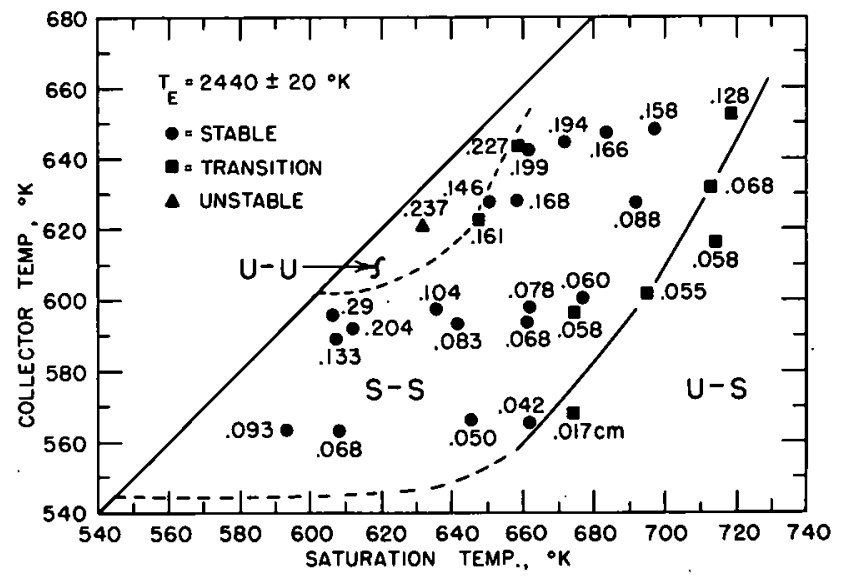

$112-4855$

On the basis of these experiments, the best operation of the diode would be in the S-S region. (7)

Brosens and Hatsopoulos (3) suggest that the Helmholtz instability in the surface separating the liquid and the moving vapor limits the 
maximum submersion. Their analysis also suggests that the permissible submersion should increase as subcooling increases. The small amount of data in region $U-U$ are not inconsistent with this view. Data points are too scarce to draw a conclusion, however. The scarcity exists because measurements were more difficult in this region. A more complicated formulation is required to successfully interpret regions $S-S$ and $U-S$.

Figures 10,11, and 12 show the maximum submersion of the emitter into the liquid cesium pool for which a satisfactory vapor film was possible. The effect of collector and pool saturation temperature is shown for three different emitter temperatures. - The data are qualitatively very similar to those for potassium, but the maximum submersion is greater and the subcooling range which is permitted for stable film boiling in this geometry is much greater. Also, with cesium an instability was observed

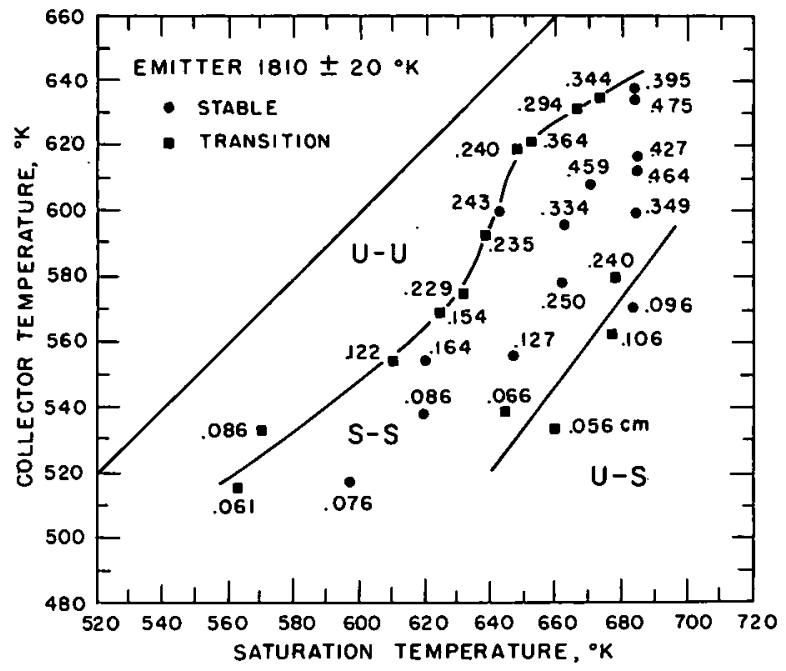

$112-4857$
Fig. 10

Effect of Emitter, Collector, and Saturation Temperatures on Maximum Submersion of Emitter in Cesium Pool, with Emitter Temperature at $1810^{\circ} \mathrm{K}$. (Numbers given are in $\mathrm{cm}$.)

\section{Fig. 11}

Effect of Emitter, Collector, and Saturation Temperatures on Maximum Submersion of Emitter in Cesium Pool, with Emitter Temperature at $2010^{\circ} \mathrm{K}$. (Numbers given are in $\mathrm{cm}$.)

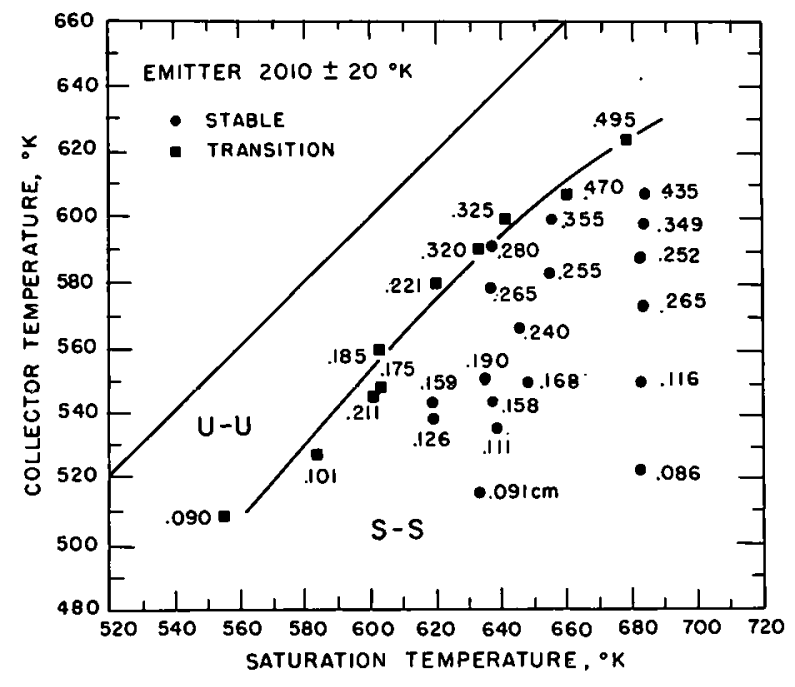

$112-4858$ 


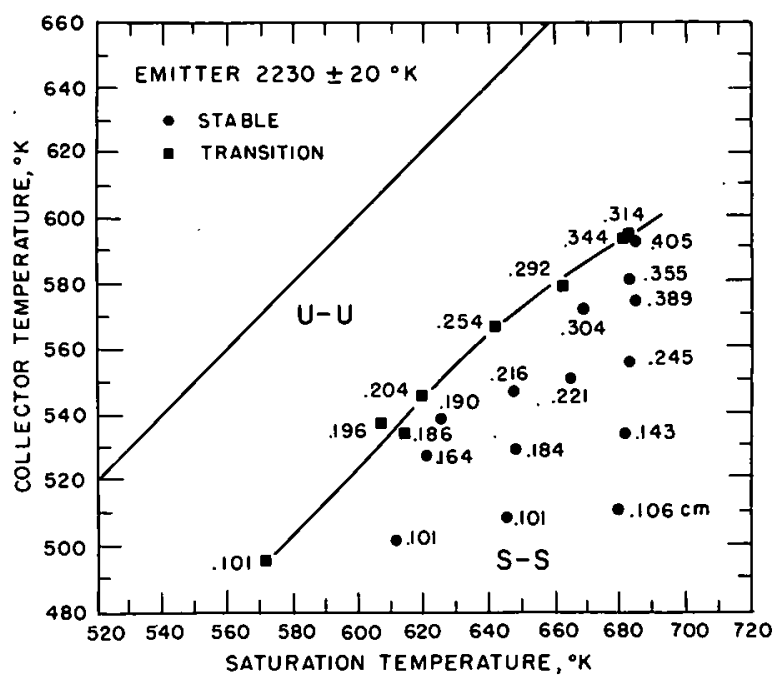

Fig. 12

Effect of Emitter, Collector, and Saturation Temperatures on Maximum Submersion of Emitter in Cesium Pool, with Emitter Temperature at $2230^{\circ} \mathrm{K}$. (Numbers given are in $\mathrm{cm}$.)

$112-4859$

at very shallow submersion for almost every datum point. For deeper submersion, the instability was suppressed. This effect was not present with potassium.

Stability conditions undoubtedly depend on the particular shape and size of the emitter and the pool. Thus, for a greatly differing geometry, another experimental study would be required. But in this case, it can be said that the permissible range of subcooling of the liquid metal is not prohibitively narrow. The few millimeters of submersion that can be tolerated eliminates the idea that a thermionic reactor using this concept can be made simply by plunging an array of fission-heated emitters into a tank of flowing liquid metal. On the other hand, the submersion that is possible shows that diodes could indeed still keep on operating if radiation damage were to warp the emitters badly.

\section{EXPERIMENTAL COMPONENT DEVELOPMENT}

The diode geometry shown in the lower part of Figure 1 requires an insulator seal. All surfaces of the emitter exposed to the bulk of the liquid metal must be in the film-boiling regime so that electrical contact between the two is avoided. If a cooler part of the emitter, which is in the transition-boiling temperature range, does contact the bulk liquid, wetting of the emitter surface and electrical shorting occur.

One possible way to handle this difficulty is to coat the cooler areas of the emitter with an electrically insulating coating. Sufficient thickness so that the outer surface of the coating is below nucleate-boiling temperature is very desirable to avoid excessive heat transfer from the emitter and to avoid violent disturbance of the film-boiling surface. Under conditions described in Section V on Experimental Study of Film-boiling Stability, these waves modulate the diode output and can even cause momentary short circuits. 
This approach was not pursued. Topologically, it is not possible for the coating to cover only the part of the emitter not in film boiling and have most of the outer surface of the coating below nucleate-boiling temperature without at the same time having a nucleate-boiling region on the surface of the coating. Also, the existence of an appropriate hightemperature coating material, with the proper expansion coefficient and resistance to thermal shock, appeared questionable.

Instead, ways of concealing the areas of transition and nucleate boiling from the bulk of the liquid by a covering of vapor were investigated. In the upper geometry of Figure 1, this is done quite naturally by means of the phase separation that occurs in the normal gravitational field. A way of maintaining a vapor sheath over these areas in other geometries using. water as a liquid was developed.(8)

An experimental arrangement, called a thermal divider, which is an extension of this work, is shown in Figure 13. In the lower part of the divider, a thimble with a flange is

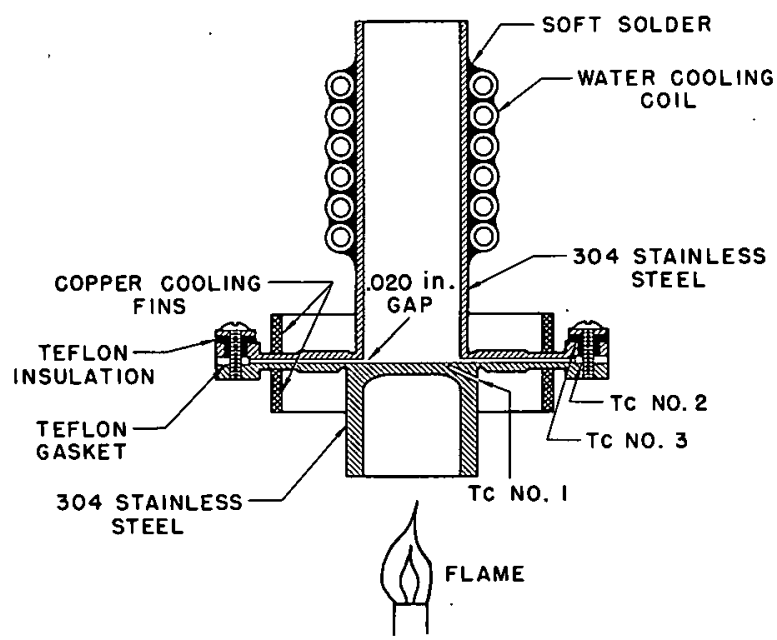

$112-4606$

Fig. 13. Thermal-divider Model Using Water as the Liquid heated by a flame so that the thimble reaches film-boiling temperature. The upper chamber with flange is electrically insulated from the lower part by the Teflon gasket. The chamber is filled with water. Heat is removed from the chamber through the cooling coil, so that the temperature of the chamber can be varied by changing the cooling-water flow.

In this arrangement, the heated thimble simulates the emitter, and the chamber filled with water simulates the diode housing with its liquid-metal electron collector. The temperature gradient between filmboiling and-nonboiling temperatures is taken along the flange radii in such a way that the nucleate-boiling areas are enclosed between the flanges and concealed from the bulk of the liquid.

Due to wetting and hydrostatic pressure, a thin layer of liquid from the chamber rounds the corner and tries to fill the 0.020-in. gap. But as the layer of liquid proceeds radially outward along the upper surface of the gap, it cannot grow thick enough to fill the gap. This is because the lower surface of the gap at the smaller radii is at film-boiling temperature. The thin layer soon encounters nucleate-boiling temperature on the upper surface of the gap and boils away. The layer is thin enough (and this is the important point) that the process is not turbulent in the usual nucleateboiling sense, and no liquid contacts both the upper and lower surfaces of 
the gap at the same time. The vapor then fills the interflange space to equilibrium pressure and flows radially. inward to condense on the bottom surface of the subcooled liquid column, filling the chamber. The bottom surface of the liquid column undulates in a slowly changing standing-wave pattern, but without electrical contact with the lower heated surface. The standing-wave pattern is not growing.in amplitude and is therefore stable according to the definition. in Section $V$ on Experimental Study of Filmboiling Stability. It could, however, modulate the output of a diode and be unacceptable. The behavior is similar to that in region U-U described in Section V. This similarity suggests that more subcooling would have reduced the standing-wave amplitude to an acceptable value.

\section{DESIGN LIMITATIONS IMPOSED BY EXPERIMENTAL RESULTS}

On the basis of the experimental information that has been developed, what form would a thermionic, energy-conversion reactor system take when it uses film-boiling, liquid-metal, electron collectors?

Since the in-core, thermionic, energy-conversion diode is the one most subject to emitter distortion, only this class will be considered.

A dominant constraint is the fact that the maximum submersion of the emitter that can be tolerated in the normal gravitational field is only a few millimeters. This is supplemented by another constraint that has almost the same effect. The vapor pressure, which has important electronic effects, varies with depth. For a system operating in a gravitational field, the collectors could be horizontal surfaces, that is, pans of liquid or liquid condensed on horizontal surfaces. Or they could take the form of vertical surfaces with liquid flowing. down the surfaces with a velocity. that is determined by the viscosity of the liquid, such as is observed in decorative fountains where a surface is sometimes covered by a uniform sheet of flowing water. Or, in a zero or very-low-acceleration field, such as would be present during.ion propulsion, the collector is free to take on a variety of shapes, its particular form being determined primarily by other factors. Because of this greater design.freedom, only. the case of very-low-acceleration field will be included here.

In the film-boiling concept, one must always be able to remove the liquid for startup and shutdown, and this adds complication to the system. Since the thermionic energy-conversion reactor is already complicated, transfer of the liquid in vapor form, which adds least complication to the system, looks most attractive and will therefore be used as the basis for further discussion.

Having now restricted the most favorable application of the filmboiling liquid-metal diode to the in-core location in a very-low-acceleration 
field environment, and using transfer of the liquid in vapor form, we may now proceed in a more detailed way.

Thermionic reactor fuel elements usually contain many diodes in series, all supplied, with cesium vapor from a common reservoir containing liquid cesium, usually located at the end of the fuel element (as shown in Figure 14). The cesium vapor pressure is determined by the temperature of the cesium liquid in the reservoir. This same basic fuel element can be used for a film-boiling, liquid-metal design. By controlling the collector temperatures within $\pm 10^{\circ} \mathrm{K}$, cesium may be condensed on the collectors in any desired thickness, the vapor being transported from the liquid-cesium source at the end of the element. The use of vapor trans-, port is mentioned in the discussion after the text contained in Reference 4. The spacing between the emitter and the liquid collector is then determined by the subcooling that is imposed.

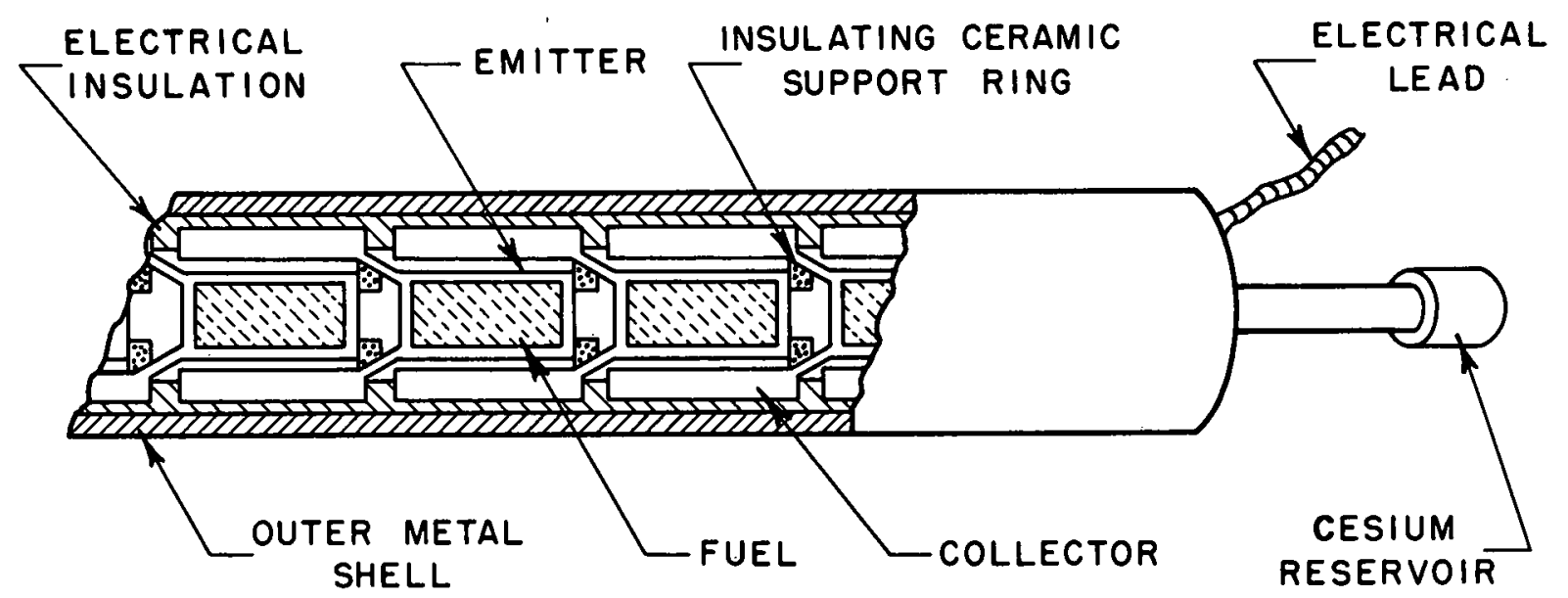

$112-4600$

Fig. 14. Cross Section of Typical In-core Thermionic Fuel Element

Is this more precise control of the collector temperatures feasible? It is certainly a restriction that one would not like to have in force, but the temperature of the emitter itself must be controlled within approximately $\pm 10^{\circ} \mathrm{K}$ if the electron emission current is to be the same for each diode in the fuel element. This restriction on emitter temperature is due to the fact that the electron emission current varies exponentially with temperature. In the case of the emitter, the heat carried away by the emitted electrons acts as a control on the emitter temperature and tends to stabilize it. Likewise, the film-boiling process itself tends to stabilize the temperature of the liquid collector; if the collector temperature goes up, the thickness of the vapor sheath increases, and the amount of heat transferred decreases, while the opposite happens if the temperature of the liquid goes down.

Thus, in this concept, the spacing between the emitter and the solid collector would be fixed at some value determined by radiation-damage 
considerations, and the spacing would then be reduced to optimum by the condensation of liquid metal on the solid collector. Subsequent changes in emitter geometry could then be accommodated within the preset limits.

The only complicating change in the construction of the conventional diode for this use would be that thermal dividers would be needed to conceal any nucleate-boiling areas which might otherwise come in contact with the liquid metal that had been condensed. This would be necessary for the two reasons mentioned in Section VI on Experimental Component Development. First, nucleate boiling of the liquid at the edge of the collector would cause too much heat transfer. Secondly, nucleate boiling at an edge of the liquid collector surface would cause violent disturbance in the surface, which could modulate the electrical output of the diode or give momentary short circuits. However, inclusion of thermal dividers would be difficult in the space available for them.

Now let us return to the reactor startup and shutdown procedure for the type of reactor that has been described. First, assume that the liquid metal is distributed in the diodes of the fuel elements in contact with the emitters, so that the maximum heat that can be transferred from the emitters by nucleate boiling exceeds the permissible nuclear heat generation rate. Then film boiling can never take place, unless the diodes are cleared of liquid metal.

The procedure for clearing the diodes is the following. The reactor coolant is pumped at a slower rate than normal, so that the electron collector surfaces and insulators can become warmer than normal. At the same time, the liquid-metal reservoir at the end of each element is kept cooler than normal. The reactor power is then increased slowly from zero. Nucleate boiling at a low rate in the diodes evaporates the liquid metal, and the vapor travels to the reservoir, where it condenses.

The reactor. is now brought to full power. With the electrodes and insulators completely dry, the emitters can reach film-boiling temperature. At this point, the reservoir temperature is slowly raised to normal and the electron collector temperatures are reduced to normal by redistributing the coolant flow. The liquid metal now evaporates from the reservoir and condenses on the electron collectors until it has reached the equilibrium thickness for the existing thermal conditions. The design of the insulators insures that the surface temperatures are high enough to prevent condensation of liquid on them. For shutdown, the procedure is reversed. The liquid metal is brought back into the reservoir, leaving dry diodes. The power can then be reduced to zero, and the reactor is prepared for restart at a later time.

The rate at which liquid can enter or leave the diodes is limited by the vapor flow area between diodes. But this flow area must be small to 
avoid large losses in an electrical discharge through the vapor between adjacent diodes. Consequently, the transfer in vapor form.is inherently slow.

Now consider the case of an emergency shutdown. Under these conditions, transfer in liquid form would be a necessity. In Section IV on Diode for Continuous Operation, it is estimated that about $2.0 \mathrm{sec}$ would elapse after a sudden shutdown before violent nucleate boiling occurred. During this time, the acceleration of liquid through the diodes and into the reservoir would increase gradually. All that can be said now, without more investigation, is that. it may or may not be possible to arrange things in such a way that the bulk of the liquid is expelled from the diodes in 20 sec. The walls of the fuel elements could probably withstand an internal pressure of 2 or 3 atm without added strengthening.

Operation of the fuel element concept as described above could only take place in a very-low-acceleration field, unless the collector surfaces were extremely small so that the surface-tension forces dominated the gravitational forces. Developmental work on such a concept could be done in a normal gravitational field, however, through the use of horizontal collector surfaces to simulate collector surfaces of other shapes. Development work for cylindrical geometry could be done by using a centrifuge to hold the liquid metal on the inside of a right circular cylinder with a vertical axis. Zero accelerations could be obtained for test purposes for about $3 \mathrm{sec}$ with a drop tower, or for about $30 \mathrm{sec}$ in an airplane flying on a zerogravity flight arc. However, a final test in an orbiting spacecraft could not be avoided.

Since a very-low-acceleration field would be associated with the space environment, one must consider the conditions imposed on this system by the necessity of heat rejection by radiation. Cesium has the proper vapor pressure for energy-conversion diodes when the temperature of the associated liquid is $600-700^{\circ} \mathrm{K}$. Heat rejection by radiation to space at this temperature is relatively inefficient. However, lithium has a vapor pressure in the right range when the temperature is about $1000^{\circ} \mathrm{K}$, which is much more suitable for radiation. Since lithium might not provide enough ions for.a neutral plasma because of its high ionization potential, the use of an alloy of perhaps.cesium and lithium would have to be considered. Then cesium.ions would be present for electron neutralization.

\section{NEEDED INVESTIGATION}

Further clarification of the feasibility of the film-boiling iliquidmetal concept would require the following information:

1. The relationship between vapor film thickness and the subcooling in film boiling. 
2. The behavior of evaporated emitter material as it is deposited on the surface of a film-boiling liquid.

3. Film- and nucleate-boiling characteristics of alkali liquidmetal alloys and compositions of their vapors.

4. Conditions for thermal stability of the vapor film for any chosen geometry.

In addition, it would be necessary to further develop the thermal divider mentioned above. The thermal-divider design would have to be very compact and not itself be subject to shorting by radiation damage in the emitter. This appears to be difficult.

Further experimentation and analysis of emergency shutdown conditions would be necessary to guide the design of a series-connected, thermionic fuel element.

More work is needed to investigate a potential advantage for the case of in-pile, series-connected diodes in a single fuel element for use in space power. The condensed liquid-metal collector can be used to provide a reliable thermal contact between the collector and the thin coating of insulation that separates the collector from the outer shell of the fuel element. For good performance in a space application, the thermal resistance to the heat flowing from the collector into the coolant must be very small. This technique may be a convenient way, to provide a thermal bond for diodes with solid electron collectors as well as liquid electron collectors.

\section{SUMMARY}

This film-boiling, liquid-metal concept is aimed at offsetting the serious radiation-damage problem that exists in the fissign-heated thermionic diode, and thus.improving the reliability of the thermionic power $r e$ actor. At the same time, the concept gives promise of ameliorating, the emitter evaporation problem. An auxiliary benefit for the case of the incore series-connected diodes in a single fuel element for use in space * power may be a much more reliable thermal bond between the collector and the coolant channel. Application of this principle to solid as well as liquid electron collectors is possible.

The price that must be paid for improved tolerance to radiation damage and emitter evaporation in this type of space application is primarily more precise control of collector temperatures, a modified startup and shutdown schedule to avoid or mitigate nucleate boiling, and successful development of a new thermal divider. 


\section{APPENDIX}

\section{Liquid-level Measurement}

Liquid-level measurement is based on the elevation readings of the reflection of the emitter in the pool, as is shown in Figure 3. Only the flat horizontal portion near. the edge of the pool gives an undistorted reflection. For deeper submersion, the pool is small enough so that no part of it is flat and a complicated correction.is necessary because of the distortion. The correction never exceeds $20 \%$ of the uncorrected value, and accuracy of the submersion is conservatively estimated to be $\pm 10 \%$. The methods of correction are described in this Appendix.

Questions about stability of the film-boiling vapor sheath are investigated by visual observation of liquid surface movements and by observation of the oscilloscope display of the current-voltage output characteristic, which is continuously monitored. Thus the recognition of stable or unstable film boiling does not depend on the liquid-level measurement.

The level of the liquid-metal pool in the diode is determined by looking at the highly reflective surface through the sight tube with a telescope mounted on a cathetometer. Elevation measurements are made for a series of points on the emitter and for the same series of points on the image of the emitter reflected from the pool. During these measurements, the angle of the line of sight with the horizontal is held constant. This angle, about $10^{\circ}$, is chosen to give the best view of reference points on the emitter and image points in the pool.

If the reflection takes place in a horizontal portion of the pool, it is a simple matter. to calculate the depth of submersion, knowing the elevation readings for the reference points, their images, and the bottom of the emitter. For submersion less than about $0.05 \mathrm{~cm}$, the depression around the emitter is small enough so that an.image can be observed on a flat, horizontal portion of the pool.

For deeper submersion, between about 0.05 and $0.25 \mathrm{~cm}$, the depression extends to the edge, and no portion of the pool is flat. This fact can be determined by observing that the differences in elevation of all pairs of image points are smaller than for the corresponding pairs of object points. The reduction of the image-point differences below the object-point differences depends on the slope of the reflecting surface and its curvature, as is indicated in Figure 3. In the geometrical-arrangement of the experiment, the observable portion of the convex profile has a curvature that increases monotonically as the point of reflection moves closer to the emitter.

The liquid level is calculated by assuming the following: As the submersion increases, the convex part of the profile of the depression moves 
outward radially without changing shape. The convex part of the profile becomes longer and extends to greater depths as submersion increases. The extension to greater depth is assumed to be provided by the curvature of the convex segment that is added near the center of the depression rather than by change of shape of the outer part of the profile. Geometrically, this means that for a particular liquid metal in this diode, the sequence of image-point elevation differences is independent of the maximum submersion. Thus, segments of plots of image-point elevation difference versus object elevation obtained from different maximum submersions may be pieced together to form one plot of image-point elevation difference versus object elevation. This plot for cesium in Figure 15 superimposes image-point elevation differences during maximum submersion for four different subcoolings and depends on overlap of the segments to define the complete curve, in compliance with the above assumption. The degree of consistency of the overlapped portions gives some confirmation of the validity of the assumption.

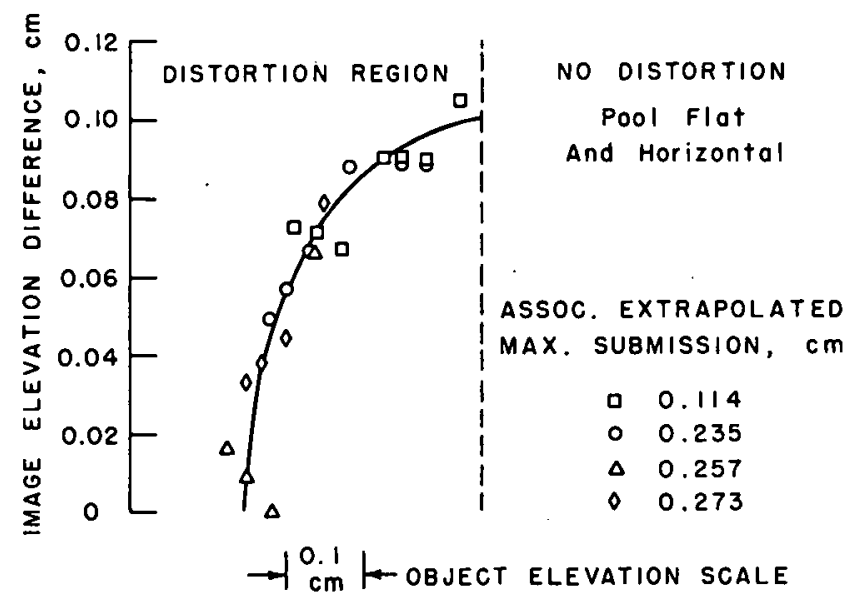

Fig. 15

Cesium Pool Reflections

Based on Object Elevation

Differences of $0.1 \mathrm{~cm}$

$112-4839$

With the complete curve defined in the above manner, it can be used to extrapolate a particular set of image-point elevation differences which are reduced by distortion. The extrapolated set is the set of image-point elevation differences that would have been observed if the pool had been large enough so that it had a flat portion around its periphery. With the elevation of the bottom of the emitter and the extrapolated set of imagepoint elevation differences, the submersion for a large pool (i.e., the extrapolated submersion) is calculated.

This process of obtaining the extrapolated set of image-point elevation differences with its assumptions obviously introduces considerable error. This correction is never more than $20 \%$ of the uncorrected submersion. Consequently, the error in the corrected submersion is conservatively estimated at $\pm 10 \%$. 
When the submersion is larger than about $0.25 \mathrm{~cm}$, most of the reference markings on the emitter are covered by liquid and an adequate set of image-point elevation differences cannot be obtained. Then the apparent submersion is used as a starting point. The elevation reading for the apparent submersion would be that corresponding to the uppermost reflected ray in Figure 3.

Figure 16 is a plot of extrapolated submersion versus apparent submersion for all data for which extrapolated submersion is available. Using this plot and the apparent submersion for a particular case, a value of extrapolated submersion may be obtained. The error in the submersion obtained by this process is also estimated to be $\pm 10 \%$.

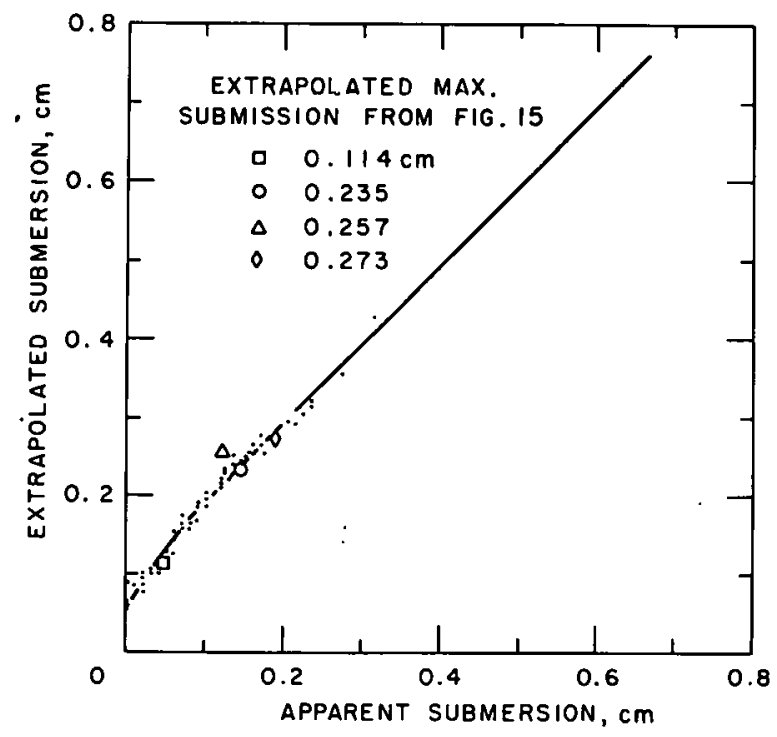

Fig. 16

Extrapolated Submersion versus Apparent Submersion in Cesium Pool

$112-4840$ 


\section{ACKNOW LEDGMENT}

The author gratefully acknowledges the able assistance of G. T. Goldfuss.

\section{REFERENCES}

1. J. C. Fischer, Thermionic Generator, U. S. Pat. 3,002,116 (Sept. 26, 1961).

2. A. J. Ulrich, Thermionic Energy Conversion Diode Using a Filmboiling, Liquid-Metal Anode, J. Appl. Phys. 33, 1896 (May. 1962).

3. P. Brosens, G. N. Hatsopoulos, Thermionic Energy Converter with a Liquid Collector, Advanced Energy Conversion 3, 387 (1963).

4. A. J. Ulrich, Thermionic Energy Conversion Diodes Using a Filmboiling, Liquid-Metal Electron Collector, Advanced Energy Conver sion 3, 397 (19.63).

5. R. E. Honig, Vapor Pressure Data for the More Common Elements, RCA Review, Vol. 18, No. 2, pp.. 195-204 (June 1957).

6. Proceedings of the Third Government-Industry Thermionic Roundtable Discussion, AD-270905, Vol. 1, Section 1, p. 13 (Jan 1962).

7. A. J. Ulrich, Stability of a Thermionic Energy Conversion Diode Using a Liquid-Metal Electron Collector, Bull. Am. Phys. Soc. 8 , 445, Paper W7 (June 1.963).

8. A. J. Ulrich, Thermionic Energy Conversion Diode Using a Filmboiling, Liquid-Metal Anode, Progress from February 1961 to September 1961; ANL-6465, p. 10 (Dec 1961). 
